\title{
Medicalización y cólera en Córdoba a fines del siglo XIX. Las epidemias de $1867-68$ y $1886-87^{1}$
}

\section{Resumen}

Una vez pasada la mitad del siglo XIX una nueva enfermedad comenzó a azotar la población argentina, generando pánico y medidas por parte del Estado a fin de combatirla. El cólera castigó a la Argentina en tres momentos en ese medio siglo: $1867-$ $68,1886-87$ y 1894-1895. Su impacto fue importante en las ciudades donde, a su vez, se producía un proceso de modernización creciente. Era también el momento en que la élite médica comenzaba una lenta pero inexorable legitimación y se encaramaba en el Estado como aspirante a custodiar la salud.

Este artículo tiene como objetivo analizar las estrategias, las prácticas y los conflictos de los diferentes actores que intervinieron en los dos primeros brotes coléricos que se produjeron en la ciudad de Córdoba. Estas epidemias cobran, en este sentido, un valor importante pues son un indicador del grado de inserción de la elite médica en el Estado y de las estrategias por las cuales opta la medicina y otros actores sociales para combatirlas. De este modo, consideramos que la conformación de ciertas instituciones, como el Consejo de Higiene Provincial y la Asistencia Pública Municipal, determinó el ascenso de la élite médica a ciertos niveles del Estado, lugares desde donde pudieron legitimarse con el desarrollo de estrategias de combate contra el cólera.

Palabras clave: Argentina, Córdoba, epidemias, cólera, medicina.

Referencia para citar este artículo: CARBONETTI, Adrián (2016). "Medicalización y cólera en Córdoba a fines del siglo XIX. Las epidemias de 1867-68 y 1886-87”. En Anuario de Historia Regional y de las Fronteras. 21 (2). pp. 285-309.

Adrián Carbonetti: Doctor en Demografía, Facultad de Ciencias Económicas, Universidad Nacional de Córdoba (UNC), Argentina. Magíster en Demografía, Centro de Estudios Avanzados, UNC. Licenciado en Historia, Facultad de Filosofía y Humanidades, UNC. Investigador Principal Centro de Investigaciones y Estudios sobre Cultura y Sociedad (CIECS)-Consejo Nacional de Investigaciones Científicas y Técnicas (CONICET), UNC. Profesor titular regular de la Facultad de Humanidades y Ciencias, Universidad Nacional del Litoral y del Centro de Estudios Avanzados, UNC.

\footnotetext{
${ }^{1}$ Esta publicación se llevó a cabo mediante el proyecto Enfermedades, epidemias y contagio. Historia de la salud y la enfermedad en Argentina y México, financiado por Programa Redes, del Ministerio de Ciencia Técnica e Innovación Productiva, Argentina.
} 


\title{
Medicalization and Cholera in Cordoba in the Late $19^{\text {th }}$ Century. The Epidemics of 1867-68 and 1886-87
}

\begin{abstract}
After the first half of the $19^{\text {th }}$ century elapsed, a new disease began to ravage the Argentine population, generating panic and measures taken by the State in order to fight it. Cholera punished Argentina three times in that half of century: 1867-68, 1886-87 and 1894-1895. It had an important impact in cities where, in turn, a growing modernization process was taking place. It was also the time when the medical elite began a slow but unavoidable legitimation and clambered in the State a candidate to become health safeguards.

This article aims to analyze the strategies, practices and conflicts of the different stakeholders who participated in the first two cholera outbreaks that occurred in the city of Cordoba. These epidemics take on significant value because they are an indicator of the degree of insertion of the medical elite in the State and the strategies chosen by medicine and other social stakeholders to fight them. Thus, we believe that the establishment of certain institutions such as the Provincial Hygiene Council and the Local Public Health Service determined the rise of the medical elite at certain levels of the State; from those places they could legitimize with the development of fighting strategies.
\end{abstract}

Keywords: Argentina, Córdoba, Epidemics, Cholera, Medicine.

\section{Medicalização e cólera em Córdoba finalizando o século XIX. As epidemias de 1867-68 e 1886-87}

\section{Resumo}

Uma vez passada a primeira metade do século XIX, uma nova doença começou a devastar a população argentina, gerando pânico e medidas por parte do Estado com a finalidade de combatê-la. A cólera castigou à Argentina em três momentos neste meio século: 1867-68, 1886-87 e 1894-1895. Seu impacto foi importante em cidades onde, por sua vez, acontecia um processo de modernização crescente. Era também o momento em que a elite médica começava uma lenta mas inexorável legitimação e se aproximava ao Estado como aspirante para custodiar a saúde.

Este artigo tem como objetivo analisar as estratégias, as práticas e os conflitos dos diferentes atores que fizeram parte dos dois primeiros brotes coléricos que aconteceram na cidade de Córdoba. Estas epidemias cobram um valor importante, pois são um indicador do nível de inserção da elite médica no Estado e das estratégias pelas quais opta a medicina e outros atores sociais para combatê-las. Desta forma, consideramos que a conformação de certas instituições, como o Conselho de Higiene Provincial e a Assistência Pública Municipal, determinou o assenso da elite médica a certos níveis do Estado, desde onde conseguiram se legitimar com o desenvolvimento de estratégias de combate.

Palavras chave: Argentina, Córdoba, epidemias, cólera, medicina. 


\section{Introducción}

Desde su existencia, las epidemias fueron fuente de conflictos y tensiones sociales. Aparecidas en momentos de crisis o generadoras de estas, las epidemias fueron elementos catalizadores de conflictos sociales y políticos ${ }^{2}$. En este sentido, el cólera es un fenómeno paradigmático: enfermedad endémica a orillas del Ganges, en momentos del desarrollo de las rutas comerciales se extendió por Occidente a principios del siglo XIX, cuando la Revolución Industrial generaba fuertes contradicciones entre las clases sociales y condiciones de vida paupérrimas en el proletariado, condiciones que determinaron una crueldad excesiva de la enfermedad en los sectores más bajos de la sociedad ${ }^{3}$. De Europa pasó a América, donde también tuvo una fuerte influencia, especialmente en las pandemias de 1833 y $1850^{4}$.

En la Argentina, el fenómeno del cólera apareció cuando el Estado se encontraba en proceso de formación ${ }^{5}$. Sus estructuras, endebles, especialmente en el sector salud, fueron rebasadas en muchos casos por la extensión y la agresividad del flagelo, pero también fueron fuente de desarrollo de instituciones y del acceso de la élite médica a ciertos ámbitos de decisión estatal que le permitieron ir consolidando su poder ${ }^{6}$. Sin embargo, esta institucionalización estuvo acompañada de un fuerte discurso segregatorio, donde los sectores populares comenzaron a ser considerados como clases peligrosas $^{7}$ por la misma medicina que se consolidaba en el Estado; conceptualización que continuará con el desarrollo de otro tipo de enfermedades ${ }^{8}$.

\footnotetext{
${ }^{2}$ Evans, Richard J. "Epidemics and revolutions: cholera in nineteenth-century Europe", en Terence, Ranger y Slack, Paul (eds.), Epidemics and ideas: essays on the historical perception of pestilence. (Cambridge: Cambridge University Press, 1992), pp. 149-173.

${ }^{3}$ Rosenberg, Charles E. "Cholera in nineteenth-century Europe: A tool for social and economic analysis", en Comparative Studies in Society and History, vol. VIII, núm. 4, 1966, pp. 452-463 y Baldwin, Peter. Contagion and the state in Europe, 1830-1930 (Cambridge: University Press, 2004).

${ }^{4}$ Existe una gran cantidad de trabajos sobre el cólera en América Latina. A modo de ejemplo: Kodama, Kaori. "Os impactos da epidemia de cólera no Rio de Janeiro (1855-56) na população escrava: considerações sobre a mortalidade a través dos registros da Santa Casa de Misericórdia", en $5^{\circ}$ Encontro escravidão $e$ liberdade no Brasil meridional. Universidade Federal do Rio Grande do Sul, Porto Alegre, 2011. Para México Cuenya, Miguel Ángel; Malvido, Elsa; Lugo, Concepción; Carrillo, Ana María; y Oliver Sánchez, Lilia. El cólera de 1833. Una nueva patología en México. Causas y efectos (México: Instituto Nacional de Antropología e Historia, 1992).

${ }^{5}$ Durante el siglo XIX, se cuentan tres episodios epidémicos: 1867-68, 1886-87 y 1894-95. Para un análisis de sus recorridos: Carbonetti, Adrián. "Los caminos del cólera en Argentina en la segunda mitad del siglo XX”, ponencia presentada en el III Congreso de la Asociación Latinoamericana de Población, Córdoba, 24 al 26 de septiembre de 2008.

${ }^{6}$ Prieto, Agustina. "Rosario. Epidemias, higiene e higienistas en la segunda mitad del siglo XIX", en Zaida Lobato, Mirta, Política, médicos y enfermedades (Editorial Biblos, 1997), pp. 56-71; González Leandri, Ricardo. "El Consejo Nacional de Higiene y la consolidación de una élite profesional al servicio del Estado. Argentina, 1880-1900", en Anuario de Estudios Americanos, t. LXI, núm. 2, 2004, pp. 571-593.

${ }^{7}$ Chaloub, Sydney. Ciudade febril. Cortiços e epidemias na Corte Imperial (São Paulo: Compania das Letras, 1996), p. 20.

${ }^{8}$ Carbonetti, Adrián. "La tuberculosis en Córdoba. La construcción de un espacio marginal”, en Estudios, Revista del Centro de Estudios Avanzados, núm. 9, 1998, pp. 73-92 y Carbonetti, Adrián. "La conformación del sistema sanitario de la Argentina: el caso de la provincia de Córdoba, 1880-1926", en Dynamis, vol. XXV, núm. 200, pp. 87-116.
} 
El desarrollo de las epidemias de cólera ha sido objeto de varias investigaciones en Argentina desde la nueva historia de la salud. González Leandri ha fijado su atención en ellas como momentos propicios para la conformación de instancias burocráticas por parte de los médicos en el seno del Estado y los conflictos que se generaron entre sus diferentes niveles 9 . Adriana Álvarez ha puesto el acento en la importancia y desarrollo de los lazaretos en momentos de producción de las epidemias de cólera y fiebre amarilla ${ }^{10}$ y ha resaltado en otro artículo el comportamiento de las epidemias a lo largo de los siglos XIX y XX en la ciudad de Buenos Aires ${ }^{11}$. Mientras que Gargullo ${ }^{12}$ y Goldman ${ }^{13}$ analizaron las políticas estatales y las formas de resistencia de los sectores populares en la provincia de Tucumán, en esta misma provincia Folquer analizó las actitudes y los discursos frente a la muerte como consecuencia del cólera ${ }^{14}$. Carbonetti y Rodríguez ${ }^{15}$ estudiaron las epidemias como una oportunidad del mercado para imponer ciertos productos que no necesariamente eran benéficos para combatirla. Por otra parte, Carbonetti las ha analizado como instancias en las que ciertos actores sociales trataban de imponerse políticamente frente a la inacción del Estado ${ }^{16}$.

En este trabajo se propone analizar las consecuencias institucionales y políticas de las epidemias de cólera en los períodos 1867-68 y 1886-87 en el marco de un profundo proceso de modernización estatal en la ciudad de Córdoba. Se parte de la hipótesis de que durante la primera epidemia (1867-68), como consecuencia de la exigua incorporación de los médicos académicos al Estado y su escasa autoridad en materia de salud, el combate contra esta estuvo signado por fuertes conflictos entre diversos actores sociales y políticos. Ahora bien, el proceso de modernización que comenzó a principios de los años 80 repercutió fuertemente en la creación y el fortalecimiento de instituciones destinadas al cuidado de la salud pública y de la fuente de consolidación de la élite médica. Sin embargo, esta consolidación estuvo signada por un discurso con una fuerte carga discriminatoria y de segregación hacia los sectores populares de la ciudad. En ese sentido, González Leandri observa que los médicos de mediados y fines del siglo XIX se destacaban por su alto nivel social, lo que les permitía, a su vez, generar vinculaciones con estamentos gubernamentales

\footnotetext{
${ }^{9}$ González Leandri, Ricardo. "La consolidación de una inteligentzia médico profesional en Argentina, 1880-1900”, en Diálogos: Revista Electrónica de Historia, vol. VII, núm. 1, 2006, pp. 36-79.

10 Álvarez, Adriana. "La aparición del cólera en Buenos Aires (Argentina), 1865-1996", en Revista Historelo, vol. IV, núm. 8, 2012, pp. 172-208.

${ }^{11}$ Ibid.

${ }^{12}$ Gargullo, María Cecilia. "El cólera: oportunidades de control y resistencias populares. Tucumán, 18861887’. En Estudios Sociales, núm. 41, 2011, pp. 97-125.

${ }^{13}$ Goldman, Noemí. "El Levantamiento de Montoneras contra «Gringos» y «Masones» en Tucumán, 1887: tradición oral y cultura popular", en Boletín del Instituto de Historia Argentina y Americana Dr. E Ravignani, tercera Serie, núm. 2, 1990, pp. 47-73.

${ }^{14}$ Folquer, Cynthia. "Colera morbus y cólera divina. Miedo a la muerte e imaginario religioso en Tucumán (Argentina) a fines del siglo XIX”, en Boletín Americanista, año LXI, núm. 62, 2011, pp. 73-96.

${ }^{15}$ Carbonetti, Adrián y Rodríguez, María Laura. "Las epidemias de cólera en Córdoba a través del periodismo: la oferta de productos preservativos y curativos durante la epidemia de 1867-1868", en Revista História, Ciências, Saúde-Manguinhos, vol. XIV, núm. 2, 2007, 405-419.

${ }^{16}$ Carbonetti, Adrián. "Cólera y conflicto en la ciudad de Córdoba, Argentina (1867-1868)”, en Boletín Mexicano de Historia y Filosofía de la Medicina, $2^{a}$ época, vol. X, núm. 2, 2007, pp. 71-78.
} 
desde los cuales tenían una fuerte inserción en el Estado ${ }^{17}$. Esta posición, tanto social como política, los transformaba en una élite que tenía cierta influencia sobre diversos sectores de la sociedad, inserción en las universidades como profesores y en algunos casos incursiones por la política partidaria.

La influencia que tenía este grupo a nivel político y social le permitió generar ciertas instituciones estatales, como el Consejo de Higiene, quienes les permitieron forjar políticas hacia la población destinadas, en estos casos, a combatir las epidemias.

La ciudad de Córdoba se transforma en un microcosmos singular para tratar de dilucidar el impacto que tuvieron las epidemias de cólera en Argentina, porque está ubicada en el margen noroeste de la región litoral y linda con las primeras estribaciones de las sierras precordilleranas. Esta posición límite entre el litoral y la región norte del país la llevó a tener una importancia fundamental en la economía del interior argentino y a conformarse en una ciudad que se insertaba en los márgenes del hinterland que había comenzado a desarrollarse con la nueva orientación de la economía argentina dirigida hacia la exportación de materias primas y la importación de capitales y bienes manufacturados ${ }^{18}$.

La consolidación en el primero de los roles señalados se configuró a partir de la inauguración del Ferrocarril Central Argentino (1870), que unía a esta capital con la ciudad de Rosario, principal puerto del interior argentino. Por otro lado, el crecimiento de la inmigración desde el otro lado del Atlántico convirtió a Córdoba en el centro administrativo de una amplia región del sur de la provincia del mismo nombre, que se poblaba y desarrollaba, justamente, por aquel fenómeno. Esto llevó a Raúl Orgaz, con razón, a considerar a Córdoba como una ciudad bifacial: semiperuana, semiplatense; aspecto que solo comenzó a definirse cuando el litoral argentino acentuó su orientación hacia el Atlántico ${ }^{19}$.

Para la realización del estudio, se ha trabajado con diversas fuentes recopiladas en los periódicos de ambos períodos, así como documentos del Archivo Histórico de la provincia de Córdoba, el Archivo Histórico Municipal de la ciudad de Córdoba y el Diario de la Residencia de Córdoba de la Compañía de Jesús, en el Archivo del Obispado de la ciudad de Córdoba. A partir de esta documentación, se hizo un entrecruzamiento y una lectura hermenéutica, desde donde se trató de analizar los conflictos, alianzas y tensiones que se dieron hacia adentro del Estado con los distintos actores políticos y sociales en ambos periodos, para hacer una comparación en relación a las acciones de la medicina actuando en y desde el Estado.

\footnotetext{
${ }^{17}$ González Leandri, Ricardo. Curar, persuadir, gobernar. La construcción histórica de la elite médica en Buenos Aires, 1852-1886 (Madrid: Editorial CSIC, 1999), p. 160.

${ }^{18}$ Boixadós, María Cristina. Las tramas de una ciudad. Córdoba entre 1870 y 1895 (Córdoba: Ferreyra, 2000).

${ }^{19}$ Angueira, María del Carmen. Transformaciones de la ciudad de Córdoba: factores operativos (18801914) (Buenos Aires: Centro Editor de América, 1988), p. 6.
} 


\section{EI desarrollo de la epidemia en la Argentina y en la ciudad de Córdoba}

En Argentina, las epidemias de cólera tuvieron un fuerte impacto sobre las poblaciones que atacaron, generando crisis de mortalidad. Su desarrollo y su crecimiento estuvieron relacionados a las condiciones higiénicas y de vida de la población, configurándose como un test de cohesión social y generando en el Estado y en la medicina una fuerte preocupación por los problemas de salud que derivaron luego en la cuestión social y también una preocupación por la higiene en el interior del país por parte de las autoridades nacionales ${ }^{20}$.

En el caso de la ciudad de Córdoba, la epidemia de 1867-68 fue la de mayor impacto social y demográfico, ya que su fuerza fue devastadora. Iniciada en el Litoral, en la primavera de 1867 , la epidemia de cólera llegó posteriormente a la provincia y ciudad de Córdoba, en el verano de 1867-68. Muchos de los poblados sufrieron una alta mortalidad como consecuencia del viajero del Ganges. Si bien no hay datos fidedignos sobre su impacto, se puede calcular aproximadamente que entre el $7 \mathrm{y}$ el 8 por ciento de la población de la ciudad de Córdoba falleció como consecuencia del cólera y entre el 2 y el 3 por ciento ${ }^{21}$ en la provincia, aunque hubo casos excepcionales de una importante mortalidad en algunas localidades como el Totoral ${ }^{22}$. Como observa Garzón Maceda, la epidemia duró aproximadamente un mes: el primer caso se diagnosticó el 15 de diciembre de 1867 y el último, el 19 de enero de 1868, mientras que en la campaña finalizaba el 27 del mismo mes ${ }^{23}$. Durante ese período, el cólera causó el terror en la población, y las huidas y las procesiones fueron las estrategias utilizadas para evitar la enfermedad. La muerte le llegó a 2.371 habitantes de la ciudad de Córdoba y a 4.000 en el total de la provincia ${ }^{24}$.

La epidemia de 1886-87 tuvo un impacto considerablemente menor sobre la población cordobesa, aproximadamente 500 defunciones, y Penna calcula que en el interior pudo darse el mismo número de muertos que en la capital, con lo que el total llegaría a 1.000 muertes, aproximadamente ${ }^{25}$.

\footnotetext{
${ }^{20}$ González Leandri, Ricardo. "El Consejo Nacional de Higiene y la consolidación de una élite profesional al servicio del Estado. Argentina, 1880-1900”, en Anuario de Estudios Americanos, t. LXI, núm. 2, 2004, p. 576.

${ }^{21}$ Penna, José. El cólera en la República Argentina (Buenos Aires: Editorial Antonio Peuser, 1897), p. 162. Penna calcula el porcentaje de muertes provocadas por el cólera en 9.7, estimando el número de habitantes de la ciudad de Córdoba en 25.000, a partir del censo de 1869. Se considera que dicha cifra, para la ciudad, en 1867, era bastante mayor, por lo cual se calcula que el porcentaje de muertes producidas por el cólera es entre el 7 y el 8 por ciento.

${ }^{22}$ Crespo Cossio, Pedro. "Aportes acerca de la incidencia de la epidemia de cólera de 1867 en el Departamento Totoral y población del mismo nombre”, en Revista de la Facultad de Ciencia Médica, vol. XXXVIII, Córdoba, 1980, pp. 41-45.

${ }^{23}$ Garzón Maceda, Félix. La medicina en Córdoba, t. III (Buenos Aires: Editorial Talleres Gráficos Rodríguez Giles, 1917), p. 677.

${ }^{24}$ Ibid., 677.

${ }^{25}$ Penna, José, Op. cit., p. 284.
} 
Cuando el cólera atacaba a la ciudad de Rosario, el gobierno provincial establecía un cordón sanitario en el pueblo de Tortugas, en el límite con la provincia de Santa Fe, donde la política impuesta era el impedimento del paso de cualquier tipo de pasajero, medida que se completaba rechazando trenes que llegaban desde esa ciudad, incluso del Regimiento núm. $5^{26}$.

Sin embargo, por orden del Ministerio del Interior de la Nación, se liberó las comunicaciones entre estas ciudades, lo que determinó el ingreso del cólera en la provincia y principalmente en la ciudad de Córdoba. La epidemia duró desde el 22 de noviembre de 1886 hasta el 25 de enero del año 1887, y en el momento en que se desarrolló se puede observar un fuerte crecimiento de la elite médica que logró insertarse en las estructuras estatales y determinar muchos aspectos de la salud pública cordobesa.

\section{La epidemia de cólera de 1867-68. Tensiones y conflictos}

Cuando aparecieron en Argentina, las epidemias de cólera se constituyeron en elementos catalizadores de una serie de fenómenos que comenzaban a aflorar en la sociedad, y especialmente en las grandes ciudades: la modernización, proceso que, según Suriano, comienza en los albores de la década de 186027; y la cuestión social, derivada de la anterior, que generaba preocupación en la elite criolla, ya que estaba surcada por la enfermedad y las epidemias, además de otras cuestiones como la obrera, la pobreza, la delincuencia, etc.

Estos dos fenómenos sociales generaron movimientos destinados a preservar la salud de la población: tal vez el más importante fue la higiene, en el que no solo intervinieron médicos sino químicos y estadísticos. Uno de los principales objetivos de este movimiento fue el de resguardar a la población de las enfermedades tanto epidémicas como endémicas mediante el saneamiento del medio urbano.

En referencia a la higiene, y justamente en relación al cólera y su necesidad de prevención, la modernización habría generado a las elites médicas un canal para la obtención de prestigio social y de recursos materiales, al permitirles incorporarse a un área de intervención pública de gran importancia ${ }^{28}$. La higiene se conformaba de esta forma en un factor relevante para el proceso de conformación de la elite médica.

Sin embargo, este proceso no se daría sin conflictos, tanto hacia adentro como hacia fuera de esta elite ${ }^{29}$. En ese sentido, es importante señalar los debates que se dieron

\footnotetext{
${ }^{26}$ Penna, José, Op. cit., p. 282.

${ }^{27}$ Suriano, Juan. "Introducción: una aproximación a la definición de la cuestión social en Argentina", en Juan Suriano (comp.), La cuestión social en la Argentina 1870-1943 (Buenos Aires: Editorial La Colmena, 2000), p. 1.

${ }^{28}$ González Leandri, Ricardo. "La higiene antes de los médicos higienistas. Buenos Aires: 1850-1870. Las epidemias”, en Desmemoria, año V, núm. 18, 1998, p. 41.

${ }^{29}$ González Leandri, Ricardo. “Académicos, doctores y aspirantes. La profesión médica y la reforma universitaria de Buenos Aires, 1871-1876”, en Entrepasados, año VI, núm. 12, 1997, pp. 31-54.
} 
en Rosario y Buenos Aires cuando comenzaba a desarrollarse la primera epidemia de cólera en Argentina, en marzo y abril de 1867, polémica publicada en periódicos y en la revista Médico Quirúrgica, acerca del origen y transmisibilidad de la enfermedad ${ }^{30}$.

Estos debates se dieron en el marco del crecimiento de la medicina como una profesión que se incorporaba al Estado, imponiendo los criterios académicos en las acciones de salud pública, en especial en las principales ciudades del litoral.

En el caso de Córdoba, la elite médica no lograba imponer sus criterios de higiene y salubridad pública. A pesar de estar inserta en el Estado, mediante el protomedicato, fue parte de una serie de conflictos, tanto hacia adentro como hacia afuera del Estado.

En un principio, se pueden clasificar estos conflictos y tensiones en cuatro niveles: a nivel intraestatal ${ }^{31}$, especialmente entre el protomédico y otros agentes estatales; entre el Estado y la Iglesia; entre el Estado y los médicos; y entre los médicos y la Iglesia.

Ante la amenaza del cólera, en el otoño e invierno de 1867, cuando atacaba la ciudad de Rosario, el Estado provincial generó medidas en dos direcciones: por un lado, facultó al protomédico Luis Warcalde para que "[...] tome dentro de esta capital y pedanías de sus suburbios, todas las medidas necesarias que tiendan a evitar la introducción y propagación de la mencionada epidemia"32. En ese mismo decreto puso a disposición del protomédico a la policía y a los jueces de Paz de la ciudad y los suburbios, y recomendaba al mismo protomédico acordar con la municipalidad las medidas para combatir el cólera. Creó, además, un Consejo de Higiene ${ }^{33}$, que tenía como misión generar la medidas necesarias para prevenir el ingreso de la epidemia en la provincia y especialmente en la misma ciudad ${ }^{34}$. Dicha comisión, para llevar a cabo su cometido, generó distintas medidas, en muchos casos de carácter restrictivo, como la imposición de cuarentenas y medidas de saneamiento del río e higienización de la ciudad. Un factor determinante para el cumplimiento de estas medidas era la acción policial. De tal forma, se impusieron establecimientos destinados a instaurar cuarentenas para viajeros que llegaban de las zonas donde reinaba la enfermedad, creando puestos dirigidos por médicos en el Pueblo de Villa Nueva y otro en las afueras de la ciudad de Córdoba, para lo cual el gobierno provincial disponía "[...] nombrar médico de policía de la Va. San Jerónimo a: Dr. Don Clodomiro Corvalan y se adjuntan el reglamento y sugerencias para desempeñar el cargo. El cargo sirve

\footnotetext{
${ }^{30}$ González Leandri, Ricardo. "La higiene antes de los médicos higienistas. Buenos Aires: 1850-1870. Las epidemias”, en Desmemoria, año V, núm. 18, 1998, pp. 49-52.

${ }^{31}$ Cuando se habla de Estado, se refiere fundamentalmente a los dos niveles estatales que se hacían cargo del combate a las epidemias: nivel provincial y nivel municipal.

32 Compilación de Leyes y Decretos de la Provincia de Córdoba, 1812-1870, p. 170. Biblioteca de la Legislatura de la Provincia de Córdoba.

33 También se lo denominaba Comisión de Higiene. Tenía un carácter coyuntural mientras durara la epidemia.

${ }^{34}$ Compilación de Leyes y Decretos de la Provincia de Córdoba, 1867, p. 281. Biblioteca de la Legislatura de la Provincia de Córdoba.
} 
para cuidar que no entren a la ciudad casos de cólera o enfermedades raras" ${ }^{35}$. La cuarentena duraba tres días antes de que los viajeros pudieran ingresar a la ciudad de Córdoba.

El personal policial tenía incumbencia, pues daba apoyo de fuerza a la cuarentena y llevaba a cabo las disposiciones del Consejo de Higiene, tanto en lo referido a la apertura de calles $^{36}$ como a la limpieza del río o la vigilancia de los establecimientos que pudieran ser peligrosos, según las teorías de transmisión de la enfermedad de la época $^{37}$. De tal forma, había una fuerte relación entre el Consejo de Higiene -donde actuaban fundamentalmente los médicos, más el presidente de la municipalidady el jefe de la policía. Fue en esta relación donde se pueden apreciar los primeros conflictos políticos provocados por la epidemia.

En mayo de 1867, dos integrantes del Consejo de Higiene, el protomédico Luis Warcalde y el presidente de la Municipalidad de Córdoba, presentaron un escrito al gobernador de la provincia por medio del cual acusaban al subintendente de policía de no cumplir ni llevar a cabo las disposiciones del Consejo de Higiene para precaverse del cólera:

El Proto-médico de la Provincia y el presidente de la Municipalidad, creen de su deber dirigirse a Usted para que se sirva elevar al conocimiento de su Excelencia lo siguiente:

Cuando tomaron sobre si la inmensa responsabilidad de dichas medidas precaucionales contra la epidemia que hoy hace estragos en los Pueblos del Litoral, sin desconocer las dificultades ni resistencias que tal género de disposiciones debían sucitar, por el carácter de novedad que tienen en este país y por la premiosa urgencia con que es indispensable llevarlas a cabo en oportunidad, no contaron sin embargo con encontrar en su camino obstáculos como las que ahora se presentan y que harán notar para que el Excelentísimo Gobierno resuelva ${ }^{38}$.

Entre las demandas realizadas por la Comisión, se encontraba el incumplimiento de las cuarentenas ${ }^{39}$, la lentitud de la apertura de las calles y la tardanza en la limpieza del río Primero ${ }^{40}$; y observaba que las obras que se llevaban a cabo, se daban únicamente

\footnotetext{
${ }^{35}$ El Eco de Córdoba, 14 de abril de 1967.

${ }^{36}$ La apertura de calles se llevaba a cabo demoliendo edificios que pudieran taponar el aire. En la época, la medicina diplomada consideraba que las corrientes de aires eran beneficiosas para la salud de la población.

${ }^{37}$ Hasta la imposición de la medicina bacteriana, una de las teorías más importantes era la miasmática, por la cual la enfermedad se transmitía a partir de olores fétidos que emanaban de diversas fuentes en la ciudad, como corrales, curtiembres, aguas estancadas, etc.

${ }^{38}$ Archivo de la Provincia de Córdoba, Libro: t. 5 (Asuntos diversos), Folios: 386 recto al 387 vuelto.

${ }^{39}$ En la nota de referencia, las autoridades de la Comisión de Higiene exponían que en los locales donde se realizaba cuarentena, se hacían bailes donde intercambiaban aquellos que se encontraban en cuarentena con los vecinos. También se acusaba al jefe de policía de sacar un niño del lazareto y llevarlo a alguna casa en el centro de la ciudad. Ibíd., folio 368-369.

${ }^{40}$ En la actualidad, río Suquía que surca la ciudad de Oeste a Este.
} 
cuando eran encargadas a particulares o cuando eran realizadas o dirigidas por miembros de la Comisión ${ }^{41}$. En esta nota se acusaba al subintendente de la policía de no obedecer las órdenes impartidas por dicha autoridad: "Esta y otras sencillísimas explicaciones, al alcance de cualquier inteligencia parecían persuadir en el momento al Jefe de Policía, pero desgraciadamente mandose (sic) por tratado de la ejecución de medidas, no ha sido así" 42 .

Esa nota derivaba en una dirigida al subintendente, por parte de las autoridades del gobierno de la provincia, para que el "Sub Intendente de Policía no se distraiga personalmente en la ejecución de las medidas referidas de higiene". Y continuaba “[...] que ponga a disposición de la Comisión de Higiene, los Comisarios y Gendarmes de Policía que dicha Comisión le pidiere, con la orden expresa de cumplir y hacer cumplir las medidas higiénicas que esta mandase"43.

Al mismo tiempo, las autoridades provinciales comunicaban a la Comisión de Higiene la nota que enviaba el subintendente de policía, quien, con una enfática defensa, intentaba mediante testimonios y el de sus subalternos preservar su posición, denunciando a la comisión por tardar en realizar las órdenes y alegando un ataque contra su persona y patriotismo ${ }^{44}$.

Estas órdenes e instrucciones por parte del gobierno de la provincia parecen no haber dado resultados significativos ya que unos días después, nuevamente, una nota por parte de uno de los integrantes de la Comisión de Higiene daba cuenta de un recrudecimiento del conflicto entre la Comisión y el subintendente de policía. En efecto, el protomédico de la Provincia, Luis Warcalde, presentaba su renuncia exponiendo que:

[...] uno de los empleados de la administración, el jefe de policía, asevera en uno de los diarios que se publica hoy en esta ciudad, que las medidas de higiene pública dictadas por la Comisión, de que el infrascrito forma parte, son con el designio de desacreditar o desprestigiar al gobierno de la Provincia ${ }^{45}$.

Esta renuncia no fue aceptada por el gobernador.

A pesar de las mediaciones que llevaba a cabo el gobierno provincial, el conflicto político entre la Comisión de Higiene y el subintendente de policía continuó, mediante notas enviadas al gobierno de la provincia en las que se lanzaban acusaciones de diverso tipo. En ese sentido, una nueva nota por parte del presidente de la Municipalidad y el protomédico de la provincia ponía en tela de juicio las acciones que llevaba a cabo el subintendente de la policía cordobesa:

\footnotetext{
${ }^{41}$ Ibid., folio $369 \mathrm{r}$.

${ }^{42}$ Ibid., folio $369 \mathrm{v}$.

${ }^{43}$ Ibid., folio $373 \mathrm{v}$.

${ }^{44}$ Ibid., folio $375 \mathrm{r}$.

${ }^{45}$ Archivo de la Provincia de Córdoba, Libro: t. 5 (asuntos diversos), Folios: 388 recto al 388 vuelto.
} 
En contestación tienen, muy a su pesar, que decir al Señor Oficial Mayor, que no pueden asumir la responsabilidad de la ejecución de las medidas, siendo ellas llevadas a cabo por la fuerza que obedece las órdenes del Señor Jefe de Policía, que es quien ha de poner a disposición de los infrascritos, según decreto, que ahora se les comunica.

Bien notoria y pública por demás, es la equivocada creencia en que aquel empleado está, respecto al rol que se incumbe desempeñar a cerca de la Comisión de Higiene: él ha comprendido que puede o no dar cumplimiento a las órdenes de dicha comisión, según a su juicio y discernimiento, las encuentra o no acertadas ${ }^{46}$.

Es decir, acusaban al jefe de policía de la provincia de tomar medidas por su cuenta. Aparentemente, la discusión culminó con una nueva mediación por parte del gobierno provincial, pues ambas partes continuaron ejerciendo sus funciones.

Este es un ejemplo de los conflictos que se generaban dentro de un Estado con escaso desarrollo y donde ciertos sectores tenían alguna autonomía, que aun siendo relativa les permitía concretar medidas y desconectarse de las órdenes de un órgano superior. En suma, se trataba de un conflicto político entre órganos estatales por la autonomía en momentos en que la epidemia de cólera, sinónimo de crisis, amenazaba la sociedad cordobesa. Por otra parte, significaba el no reconocimiento de los médicos, principales integrantes de la Comisión de Higiene, como los agentes fundamentales para el combate contra la enfermedad.

Sin embargo, este no fue el único trance. En los diversos documentos se pueden apreciar tensiones entre el Estado, los médicos que se encontraban a sus órdenes y la Iglesia. En efecto, en otro escrito se expuso que la Iglesia fue la única institución que, por su grado de inserción social, su capital monetario y su organización, logró poner sus recursos humanos y su mobiliario al servicio de los enfermos, y también fue la única institución social que logró sacar rédito político y social una vez que la epidemia desapareció de la ciudad de Córdoba. Esta cohesión le permitió también un grado importante de autonomía en sus iniciativas, que en muchos casos entraban en conflicto con las teorías médicas acerca de la transmisión de la enfermedad y que determinaban las medidas a ser tomadas para evitar el contagio ${ }^{47}$.

De esta forma, la Iglesia puso a disposición de la sociedad cordobesa sus recursos humanos y materiales ${ }^{48}$, acordando con el Estado la atención de enfermos y logrando, por otro lado, desarrollar actividades que iban en contra de las disposiciones emanadas por los médicos, especialmente el protomédico. Al mismo tiempo, actuaba como un

\footnotetext{
${ }^{46}$ Archivo de la Provincia de Córdoba. Libro: t. 5 (asuntos diversos). Folios: 389 recto al 390 recto.

${ }^{47}$ Carbonetti, Adrián. "Políticas estatales y medicina frente a la epidemia de cólera de 1867-68 en Córdoba y Rosario", en Adrián Carbonetti (comp.), Historias de enfermedad en Córdoba desde la colonia hasta el siglo XX. (Córdoba: Editorial de la Municipalidad de Córdoba, 2007), p. 34.

${ }^{48}$ La Iglesia se encargó de la atención de los lazaretos y la atención de los enfermos en sus casas. Archivo Histórico de la Municipalidad de Córdoba, Libro 2.A.6, F580, 27 de diciembre de1867, y Diario de la Residencia de Córdoba de la Compañía de Jesús, t. 1 (1859-1868), f. 177 v.
} 
organismo paraestatal, pues lograba y obtenía, mediante quejas, el auxilio del Estado. De esta forma, se pueden apreciar tensiones importantes entre la postura emitida por el protomédico y la Iglesia.

Entre las disposiciones que emitió el protomédico para la lucha contra el cólera-en los primeros meses de 1867, cuando el cólera amenazaba a la provincia ${ }^{49}$, y luego cuando se desató la enfermedad ${ }^{50}$, se encontraban una serie de recomendaciones que iban desde una alimentación frugal, el aseo personal y de las habitaciones, hasta conservar el ánimo alto y no "tener miedo al cólera" y la prohibición de realizar reuniones donde se acumulara una gran cantidad de personas. Sin embargo, durante la epidemia se llevaron a cabo procesiones y sus respectivas misas, aunque iban en contra de las disposiciones generales del protomédico y de la Comisión de Higiene ${ }^{51}$. Estas contradicciones no eran nuevas, en América Latina se pueden encontrar ejemplos de tensiones entre el Estado y la Iglesia frente a las epidemias y sus formas de enfrentar el flagelo ${ }^{52}$.

Pero en los periódicos se pueden apreciar también varios indicadores de las tensiones en las que una institución cohesionada como la Iglesia contradecía las recomendaciones de los médicos, especialmente del protomédico, que era, a su vez, la voz del Estado en esos momentos. En ese sentido se puede apreciar una editorial en el periódico El Eco de Córdoba, un escrito de un integrante de la Iglesia:
Las vanas y ridiculas teorías muestran su desnudes, su esterilidad, porque no bastan para inspirar ni siquiera para [término ilegible] ideas consoladoras; todo lo contrario de aquellos sanos consejos del Evangelio y del culto sencillo y grave del catolicismo, que tiene para cada herida del alma una medicina eficaz y saludable.
Por eso los heraldos de la mentira no hacen propaganda en las aras de profunda y general tristeza, y el pueblo que casi nunca se extravia, asiste con devoción al templo a pedir a Dios el remedio de los males que se afligen ${ }^{53}$.

Al actuar la Iglesia como un órgano paraestatal, ya que fueron varios los lazaretos que se conformaron en sus inmuebles, se generaron tensiones en lo referido a la atención de los pacientes. Un indicador de este tipo de tirantez se puede apreciar en una carta enviada por el comendador de la Orden de los Mercedarios, donde se había emplazado un lazareto, que se quejaba frente al Presidente de la municipalidad por las condiciones en que debían trabajar, atendiendo enfermos sin ningún tipo de ayuda por

\footnotetext{
${ }^{49}$ El Eco de Córdoba, 14 de abril de 1867.

${ }^{50}$ Archivo de la Provincia de Córdoba. Libro: t. 5 Asuntos Diversos. Folios: 411 recto al 412 recto.

${ }^{51}$ Durante el desarrollo de la epidemia, se pueden contabilizar por lo menos dos procesiones. El Eco de Córdoba, 5 de enero de 1868 y 18 de enero de 1868.

${ }^{52}$ Carrillo, Ana María. "La epidemia de cólera de 1833 en el Estado de México”, en Miguel Ángel Cuenya, et al, El cólera de 1833. una nueva patología en México. Causas y efectos. (México: Instituto Nacional de Antropología e Historia, 1992), pp. 65-87.

${ }^{53}$ El Eco de Córdoba, 18 de enero de 1868.
} 
parte del Estado. "Por resolución de esa corporación he establecido un lazareto en este convento en el cual se encuentra un número de pacientes atacados de la epidemia al cual no puede atenderse convenientemente por carecer de camas, médicos, medicinas y demás" ${ }^{54}$.

El mercedario amenazaba con dejar los cadáveres al aire libre en caso de que empleados de la municipalidad no los recogieran. Nuevamente, se observa en estos párrafos que existían tensiones entre la Iglesia y el Estado, aunque aquella actuara como un brazo de este, estableciendo lazaretos. Se trataba, sin duda, de una tirantez que era potenciada por la epidemia como sinónimo de crisis, lo que ampliaba los reclamos hacia el Estado, en ese momento incapaz de satisfacerlos, y donde la Iglesia lograba el mayor rédito político ${ }^{55}$.

Estos reclamos no solo venían desde la Iglesia, también los médicos entraban en tensión con el Estado frente a las diversas medidas que tomaba el gobierno para enfrentar al cólera en momentos que la epidemia arrasaba con la población. La ubicación de los lazaretos y la atención de los enfermos eran parte de las dificultades que se encontraban y que eran causa de escritos por parte de aquellos o de denuncias por parte de la misma policía.

En momentos que se desataba la epidemia, la municipalidad de Córdoba expropiaba un molino alejado de la ciudad y cercano al cementerio a fin de ser utilizado como lazareto. Eso levantó voces de reclamos por parte de algunos médicos que se negaron a atender a los enfermos en aquel lugar, ya que se encontraba demasiado lejos de la ciudad y su acceso era dificultoso. En una carta firmada por el doctor León Molina, se puede apreciar la negativa del médico a concurrir a ese lugar:

Sr. Presidente de la Municipalidad de Córdoba. Habiendo revisado el local adonde está colocado actualmente el lazareto de los coléricos tengo el honor de informar a Ud. que aquel lugar no es apto para el fin que ha sido destinado, tanto por estado de la casa como por los caminos que son pésimos, como por la distancia, de modos que yo no puedo comprometer de ninguna manera a asistir a los afectados allá ${ }^{56}$.

Este médico era uno de los actores en la atención de enfermos de cólera y una de las principales figuras dentro del cuerpo de médicos que actuaban en la ciudad de Córdoba, y por lo tanto muy respetado, es decir, era una de las voces que escuchaba el Estado a la hora de tomar medidas. Sin embargo, esta negativa para la atención de enfermos no es la única: en el archivo de la Municipalidad de Córdoba se pueden encontrar ejemplos de negativas por parte de los médicos, que en última instancias eran obligados por la fuerza pública:

\footnotetext{
${ }^{54}$ Archivo Histórico de la Municipalidad de Córdoba. Libro 2.A.6, F580, 27/12/1867.

${ }_{55}$ Este tema fue tratado en una ponencia presentada en Carbonetti, Adrián (2007). "Políticas estatales y medicina frente a la epidemia de cólera de 1867-68 en Córdoba y Rosario", en Adrián Carbonetti (comp.), Historias de enfermedad en Córdoba desde la colonia hasta el siglo XX (Córdoba: Editorial de la Municipalidad de Córdoba).

${ }^{56}$ Archivo Histórico de la Municipalidad de Córdoba. Libro A.2.6, F512, 16 de diciembre de 1967.
} 
Medicalización y cólera en Córdoba a fines del siglo XIX. Las epidemias...

Acabo de tener aviso del Comisario de la 2da sección que según le han dicho los Comisario de la Municipalidad Tufato y López, los médicos que se han visto para que atendieran a los coléricos se han negado a asistir a excepción de D. León.

También debo decir a usted que se hace indispensable que se pusiera un médico por lo menos en cada sección y en caso no acepte (sic) [...] servirá indicarme cuales son para obligarlos a que presten sus servicios ${ }^{57}$.

En estos casos, el Estado era obligado a actuar con la fuerza pública ya que en momentos de crisis - como esta epidemia, que causaba tantas muertes- muchos habitantes huían de la ciudad, entre ellos los médicos que, según el Estado, eran los encargados de cuidar la salud de la población. Un ejemplo fue el doctor Cuestas, que al descubrir el primer caso de cólera huyó de la ciudad ${ }^{58}$.

Ahora bien, la escasa presencia médica y las disputas generadas entre los diferentes actores sociales, estaban también enmarcadas por una visión donde la inclusión de la población era un elemento fundamental. Como los riesgos de contraer el cólera se expandían a toda la sociedad, la epidemia se transformaba en una dolencia igualitaria: todos los sectores sociales podían ser víctimas y, a su vez, victimarios, por transmitir la enfermedad.

Un ejemplo de ello es la publicación en el periódico El Eco de Córdoba, cuando el cólera hacía estragos en Rosario, y generaba un fuerte temor en la población de la ciudad de Córdoba, de una carta de Warcalde al gobernador, dando consejos de las medidas que debían tomarse para contener la invasión del cólera en la ciudad. En el extenso escrito se pueden apreciar tanto medidas de carácter público como aquellas destinadas al cuidado individual. Entre las primeras, se establecía la vigilancia en lugares públicos y establecimientos que pudieran transformarse en focos de infección, como corrales, mataderos, paseos, hospitales, etc. También, sugería vigilar el estado de los alimentos, disponer la denuncia de casos de cualquier tipo de dolencia parecida al cólera y buscar un paraje donde depositar la basura. Ponía a cargo de la denuncia de la enfermedad a médicos y boticarios y prohibía la acción de los curanderos, además de crear una Comisión de Higiene Pública, que no tenía existencia en Córdoba. Esta institución estaba destinada a tomar medidas sanitarias que debían cumplirse mediante la fuerza pública. Como se puede apreciar, no se encuentran indicios donde las clases sociales tuvieran algún tipo de estigmatización. Por el contrario, la población fue observada por los médicos, la Iglesia y el Estado sin diferenciación de clases.

La Municipalidad también publicó consejos a la población en su totalidad, lo que confirma la hipótesis:

Consejos al pueblo: medidas higiénicas

El mayor aseo en las personas, vestidos y habitaciones.

\footnotetext{
${ }^{57}$ Archivo Histórico de la Municipalidad de Córdoba. Libro A.2.6, F511, 13 de diciembre de 1967.

${ }^{58}$ El Eco de Córdoba, 2 de febrero de 1868.
} 
El abrigo especialmente en el vientre y pies.

Ejercicio moderado al aire libre, a pie, a caballo o en carruaje evitando la insolación excesiva, frío, la humedad y la fatiga.

La habitación en piezas espaciosas, bien ventiladas y secas.

Renovación frecuente de habitaciones estrechas.

Uso del fuego en piezas húmedas.

Blanqueo de las casas especialmente en dormitorios.

La proporción entre el número de personas que habitan las casas y la capacidad de estas, evitando el hacinamiento especialmente en la noche.

Extracción diaria de basuras y de los restos de animales y vegetales que deben conservarse a la sombra y bien encubiertos mientras no se utilicen.

La alimentación frugal a horas regulares, prefiriéndose las carnes frescas, los huevos pasados por agua y blandos, el pan, el vino, el caldo, el café y vino y prescribiéndose el abuso de licores espirituosos y todo alimento que exija una digestión laboriosa, especialmente ácidos fuertes, sustancias grasosas, fiambres, coles, hongos, pepinos, encurtidos preparados de cerdo, escabeches y mariscos. La abstención absoluta de las frutas y de todo remedio que no sea prescrito por un médico.

La más perfecta regularidad de las funciones digestivas.

Sueño a la hora de costumbre, suficiente para reparar fuerzas, pero no muy prolongado.

Tranquilidad del espíritu, cuanto que las pasiones deprimentes y la aprensión de enfermarse, predisponen la epidemia. Los ebrios, los gastrónomos y los libertinos han sido siempre los predilectos de estas enfermedades, ellos deben evitar los desvíos de régimen, ateniéndose a los consejos antes formulados. Las personas que observen regularidad y templanza en todos los actos de su vida, serán respetados por la enfermedad..$^{59}$

Estos consejos eran para toda la sociedad cordobesa, sin discriminación de clase. Sin embargo, es indudable que aquellos sectores que se encontraban en la cúspide de la pirámide social tuvieron las mejores oportunidades para evadir la enfermedad, especialmente a través de la huida.

Los conflictos antes mencionados son evidencia de que la medicina aún no había logrado insertarse en el Estado. Por otra parte, este era muy débil para lograr imponerse tanto hacia adentro como hacia afuera, aún debían darse cambios en la estructura estatal y un fuerte proceso de medicalización para que se produjera una estructura que consolidase al Estado y a la élite médica como autoridades reconocidas en términos de la salud. Sin embargo, este estaría impregnado de fuertes concepciones clasistas y discriminatorias.

\section{La epidemia de 1886-87 y la consolidación de la élite médica}

En 1897, José Penna expresaba que una epidemia siempre es una desgracia popular. Sin embargo, con una mirada optimista, las consideraba una oportunidad para la consolidación de instituciones donde intervenían médicos, destinados a la salud pública:

${ }^{59}$ El Eco de Córdoba, 14 de abril de 1867. 
[...] que sean bienvenidas, si como esta nos ha de dejar planteadas y resueltas esas hermosas conquistas de la higiene, como la cremación obligatoria en las casos de enfermedades transmisibles, la creación del Instituto de Bacteriología, el afianzamiento de la Asistencia Pública, la creación de hospitales de aislamiento, y, sobre todo esto, el conocimiento en el vulgo de que las enfermedades transimisibles son evitables ${ }^{60}$.

Este parece haber sido el caso de la provincia de Córdoba ya que, cuando la ciudad y la provincia se vieron nuevamente amenazadas por el cólera en la primavera/ verano de 1886-87, la situación había cambiado radicalmente. El protomédico había sido sustituido por un Consejo de Higiene Pública que se encontraba dirigido por médicos, se había creado la Facultad de Ciencias Médicas en el ámbito de la Universidad Nacional de Córdoba en 1878, y funcionaba también en la ciudad un cuerpo de Asistencia Pública Municipal. En todas estas instituciones, actuaban y estaban dirigidas por médicos, en la mayoría de los casos su prestigio devenía de ser profesores de la Facultad. Este era el resultado de un vasto proceso de inserción de la élite médica en diversos ámbitos del Estado, así como de la institucionalización de sus prácticas ${ }^{61}$. A esto se agregaba un mayor número de médicos: si hacia 1869 actuaban en toda la provincia 40 galenos, hacia 1895 se había casi triplicado en 112 . Se considera que este proceso de institucionalización de la medicina permitió una acción mayor de los médicos frente a la epidemia, contando para esto con el apoyo total del Estado provincial y municipal, y significó también la expansión de la élite médica en diversos ámbitos de la acción estatal. Las disposiciones del Consejo de Higiene eran escuchadas por la autoridad gubernamental y llevadas a cabo sin resistencia de los otros sectores del Estado, como no había sucedido en la epidemia anterior.

En el decreto del 28 de marzo de 1881, el gobernador Juárez Celman aprovechaba la oportunidad de la renuncia del protomédico para derogar, por innecesaria, esta institución. Justificaba dicha acción por la existencia de la Facultad de Ciencias Médicas y decretaba la organización del Consejo de Higiene, que a partir de las palabras del gobernador se conformaba en el ente regulador de las prácticas de la salud, apuntalado por la incipiente élite médica vinculada a la universidad ${ }^{62}$. Una de las características que tuvo el Consejo fue el de actuar fundamentalmente en el ámbito de la ciudad de Córdoba.

En el municipio de Córdoba, esta epidemia fue aprovechada por la medicina para generar cambios en la ciudad, especialmente en los barrios habitados por pobres, debido a que tanto la zona en que residían como los mismos pobladores eran considerados por la elite médica como fuente de contagio. Estas poblaciones fueron parte de un plan de erradicación debido a las condiciones en que vivían. En el

\footnotetext{
${ }^{60}$ Penna, José. El cólera en la República Argentina (Buenos Aires: Editorial Antonio Peuser, 1897), pp. 195 y 196.

${ }^{61}$ Carbonetti, Adrián. "La conformación del sistema sanitario de la Argentina: el caso de la provincia de Córdoba, 1880-1926”, en Dynamis. Acta Hispanica ad Medicinae Scientiarumque Historiam Illustrandam, vol. 25, 2005, p. 96.

${ }^{62}$ Ibid.
} 
documento elaborado por las autoridades del Consejo de Higiene, dicha determinación se justifica por el hacinamiento, la falta de higiene personal y de las habitaciones, pero fundamentalmente la problemática ambiental:

[...] la parte de la población conglomerada en el bajo del Río al Norte, por su hacinamiento y falta de aseo en sus personas y habitaciones, pero más que nada, el bajo nivel de dicha localidad y la circunstancia de encontrarse tapizado, puede decirse de desperdicios de toda naturaleza ${ }^{63}$.

Los habitantes de esa zona debían ser trasladados, sin consultarlos. En ese sentido, el Consejo de Higiene de la provincia también programaba el lugar donde debían ser reubicados, lo que deja claro la fuerte carga de discriminación y segregación hacia esos sectores pobres:

Hacer desalojar Señor ministro dicha localidad y hacer destruir por los medios más eficaces y económicos toda su edificación, eligiendo un punto al Nord-Este de la ciudad distante diez cuadras de las últimas poblaciones de esa dirección, sumando las medidas consiguientes a fin de prevenir la aglomeración en el nuevo punto, fijándoles o delineándoles por manzanas donde puedan levantarse las nuevas habitaciones ${ }^{64}$.

Las condiciones de aseo y habitación de esa población la transformaban, antes de que se declarara la epidemia, en clases peligrosas ${ }^{65}$ que debían ser erradicadas de los lugares cercanos a la ciudad y situadas en lugares lo suficientemente lejanos como para que no se contactaran con los habitantes del centro. El Consejo de Higiene, desde esta perspectiva, apoyado por el Estado provincial, le daba a la enfermedad un carácter eminentemente social, lo que generaba una nueva estructura dentro de la traza urbana con ciertas características de ghetto, pues la distancia no daba lugar a un contacto frecuente entre aquellos pobladores erradicados y los que habitaban el centro. El carácter violento que tomaría la medida fue justificado por la urgencia de la situación ${ }^{66}$.

Es interesante observar que el Consejo de Higiene reiteraba en este documento la inacción de la corporación municipal frente a sus reiteradas solicitudes para llevar a cabo la erradicación de esa población antes de que el cólera amenazara Córdoba, lo que de alguna manera planteaba ciertas tensiones del Consejo con la intendencia municipal.

La cárcel era el otro lugar donde la élite médica ponía sus ojos como un terreno habitado por clases peligrosas. En ese sentido, el presidente del Consejo de Higiene realizó una visita a ese establecimiento y observó los problemas estructurales que podrían derivar

\footnotetext{
${ }^{63}$ Archivo Histórico de la Provincia de Córdoba. Serie Gobierno, t. 7, Folio 93 A. Octubre de 1886.

${ }^{64}$ Archivo Histórico de la Provincia de Córdoba. Serie Gobierno, t. 7, Folio 93 r. Octubre de 1886.

${ }^{65}$ Chevallier, Luis. Classes laborieuses et classes dangereuses à Paris pendant la première moitié du XIXe siècle (Perrin: 1958, rééd. aux Plon, 2002).

${ }^{66}$ Archivo Histórico de la Provincia de Córdoba. Serie Gobierno, t. 7, Folio 94 v. Octubre de 1886.
} 
el comienzo y el desarrollo de una crisis epidémica en toda la población. El presidente del Consejo de Higiene observaba que la cárcel, por el hacinamiento y las condiciones en las que vivían los reclusos, podía considerarse como un establecimiento insalubre de primera clase y proponía el desalojo y el traslado de los presos a otro establecimiento.

Entre las medidas que proponía, se encontraba el blanqueo a la cal del edifico, cegar las letrinas existentes y hacer otras nuevas, y disminuir el número de internos; a eso agregaba que el médico de policía llevara a cabo una inspección diaria sobre la salubridad del local ${ }^{67}$. En este caso, también el Consejo de Higiene dejaba constancia del incumplimiento de la orden de blanquear el edificio ${ }^{68}$.

Se puede apreciar, en este sentido, que el Consejo de Higiene expresaba una hiperactividad creciente. Indudablemente, en principio la epidemia de cólera era un factor fundamental para esta hiperactividad, también que era parte de la necesidad que tenía esta élite médica de consolidarse en ciertos bolsones del Estado desde donde vigilar la salud de la población, era una forma de legitimación a partir de la acción.

El tercer factor que el Consejo de Higiene observó como un riesgo para la introducción y desarrollo del cólera fueron los viajeros que llegarían desde el litoral. Para ello proponía una serie de medidas que se ejecutaron a cabo sin ningún tipo de discusión desde el órgano ejecutivo. Ese celo no se detenía únicamente en los pasajeros, sino también en todo elemento que pudiera llegar desde aquella región, así que se prohibió el ingreso de trenes desde Santa Fe, con la única excepción de aquellos que ingresaran carbón y desinfectantes; se obligó a la desinfección de los vagones que incluso circularan dentro de la provincia; y se prohibió el ingreso de correspondencia desde el litoral ${ }^{69}$. Los pasajeros debían, a su vez, atravesar una serie de procedimientos que iban desde la cuarentena, pasando por la observación durante dos días y la inspección médica, hasta la fumigación de ellos mismos y de los bagajes que los transportaban ${ }^{70}$. Si bien estos procedimientos se hacían antes del ingreso de la epidemia a la provincia, luego de desatada, y cuando se desarrollaba en Mendoza y Tucumán, también el Consejo de Higiene proponía formación de casas de observación en los pueblos de Villa María ${ }^{71}$ y Quilino ${ }^{72}$ a fin de que "[...] vigilen, controlen y detengan a todo pasajero procedente de dichos puntos para este destino"73.

Pese a todas las medidas, la temida epidemia ingresó en la ciudad y el Consejo de Higiene Pública fue el encargado de dar la noticia a las autoridades de la provincia y a la sociedad cordobesa. El anuncio estuvo cargado de una fuerte cientificidad, que denotaba también la adjudicación del monopolio del saber.

\footnotetext{
${ }^{67}$ Archivo Histórico de la Provincia de Córdoba. Serie Gobierno, t. 7, Folio 96 v. Octubre de 1886.

${ }^{68}$ Archivo Histórico de la Provincia de Córdoba. Serie Gobierno, t. 7, Folio 95 r. Octubre de 1886.

${ }^{69}$ Archivo Histórico de la Provincia de Córdoba. Serie Gobierno, t. 7, Folio 225 A. Febrero de 1887.

${ }^{70}$ Archivo Histórico de la Provincia de Córdoba. Serie Gobierno, t. 7, Folio 106 A. 11 de Noviembre de 1886.

${ }^{71}$ Pueblo ubicado el sur este de la provincia de Córdoba.

72 Pueblo ubicado al norte de la ciudad de Córdoba.

${ }^{73}$ Archivo Histórico de la Provincia de Córdoba. Serie Gobierno, t. 7, Folio 133 A. 27 de Diciembre de 1886.
} 
Del conocimiento adquirido por miembros de este consejo, de los casos de enfermedad que vienen denunciándose diariamente a la autoridad municipal, i teniendo presente todo lo que en el desarrollo de los procesos morbígenos se observa, en lo referente a la etiología, formas clínicas i anátomo patológicas, de la enfermedad que se estudia, manera de su terminación, concordando por las observaciones autópsicas i examenes microbiológicos (sic $)^{74}$.

A partir de estas palabras, el Consejo de Higiene declaraba la introducción del cólera asiático en la ciudad basado en el examen de varios casos sospechosos. Es importante aclarar que el consejo culpaba a aquellos que habían enfermado de la introducción de la epidemia en la ciudad de Córdoba a partir de la inobservación de las prescripciones sobre higiene pública y privada ${ }^{75}$. Observaba que los primeros infectados que pertenecían a los sectores populares de la ciudad, eran aquellos que inexorablemente debían enfermar e introducir la dolencia en la urbe mediterránea, confirmando de alguna manera los postulados de clases peligrosas, de acuerdo a las medidas que había tomado antes de la llegada del cólera. Este dato se corroboraba cuando el Consejo de Higiene exponía al gobierno las instrucciones ideadas para combatir al cólera. En el artículo 7 se pretendía la conformación de un cuerpo de fumigadores y desinfectadores que, estando a cargo del consejo, debería principalmente fumigar las rancherías de la ciudad ${ }^{76}$. Por otro lado, al finalizar la epidemia, el doctor Luis Rossi, presidente del Consejo de Higiene, en una memoria enviada al gobierno de la provincia de Córdoba, indicaba las instrucciones que había dado al intendente, y dentro de estas se encontraba una por la cual se nombraba a dos personas por manzana, encargadas de mantener la higiene de la población, además de una que llama la atención: "Mantener el menor contacto posible con los moradores de los alrededores de la ciudad" "77, es decir los pobres que vivían en los ranchos.

Como se puede apreciar, todas las medidas estaban dirigidas desde dos factores esenciales que podrían generar la enfermedad: los forasteros y los pobres.

No obstante el poder que había logrado el Consejo de Higiene y las contundentes medidas que se aplicaban, la sociedad generaba acciones que penetraban los capilares de esta política aplicada por el Estado. Es el caso de los pasajeros de los trenes que arribaban a la ciudad de Córdoba. En una carta que enviaba el jefe del equipo de fumigadores al doctor Rossi, con fecha del 3 de enero de 1887, el primero denunciaba a la compañía de trenes y a los pasajeros de evadir la fumigación obligatoria, deteniendo el tren en otro punto al destinado, con lo cual se permitía que el pasaje pudiera descender, eludiendo las medidas establecidas. En esa misma carta, el fumigador denunciaba que estas estrategias se habían realizado varias veces ${ }^{78}$.

\footnotetext{
${ }^{74}$ Archivo Histórico de la Provincia de Córdoba. Serie Gobierno, t. 7, Folio 99 R y 100 A. 24 de Noviembre de 1886 .

${ }^{75}$ Archivo Histórico de la Provincia de Córdoba. Serie Gobierno, t. 7, Folio 100 R. 24 de Noviembre de 1886.

${ }^{76}$ Archivo Histórico de la Provincia de Córdoba. Serie Gobierno, t. 7, Folio 113 A. 29 de Noviembre de 1886.

${ }^{77}$ Archivo Histórico de la Provincia de Córdoba. Serie Gobierno, t. 7, Folio N 7226 A. Febrero de 1887.

${ }^{78}$ Archivo Histórico de la Provincia de Córdoba. Serie de Gobierno t. 7, Folio 197 A y 197 V. 3 de enero de 1887.
} 
Frente a las acciones que se llevaban a cabo con las clases peligrosas, hubo reacciones, especialmente de la prensa: El diario El Porvenir, en su edición del 24 de noviembre de 1886, acusó al Consejo de Higiene de quemar los ranchos de los que morían de cólera y se preguntaba: “Si muriera un rico, les quemarían también su palacio y muebles preciosos?"79.

Estas no fueron las únicas desobediencias a la palabra de los médicos: el 28 de noviembre de 1886, el Vicario Capitular, Monseñor Dr. Vladislao Castellano, invitaba al pueblo a realizar una procesión pese a las prohibiciones que había encomendado el Consejo de Higiene.

Cuando la epidemia se desató, el Consejo de Higiene no se salió de los cánones que estipulaba la medicina occidental: la división de la ciudad a cargo de médicos académicos y dos estudiantes de la Facultad de Ciencias Médicas, que hacían las veces de practicantes, en cada sección.

La ciudad se dividió en ocho secciones: las cuatro primeras estaban ubicadas en el centro de la ciudad y las otras cuatro, en los alrededores. En ese sentido, se ponía el acento en el número de habitantes pero también en la clase social a la que pertenecían los habitantes de las distintas secciones. Las zonas centrales estaban integradas por pocas manzanas, mientras las distancias a recorrer en las secciones periféricas eran mucho mayores. Esto se puede apreciar en el plano de la ciudad de Córdoba de 1890, donde se ha adaptado las secciones a las cuales se hace referencia.

Esta división de la ciudad -en la cual los sectores más humildes llevaban una fuerte carga de discriminación y escasa atención médica, ya que se disponía del mismo número de médicos y practicantes para las diferentes secciones-, se incrementó con el emplazamiento de los lazaretos. En ese sentido, se instalaron en la ciudad cuatro lazaretos: uno administrado por el Consejo de Higiene y financiado por el Estado Provincial, en Pueblo San Vicente; otro administrado por la municipalidad de Córdoba, situado en lo que se denominaba la Bajada del Pucará -ambos se encontraban en las afueras de la ciudad-; y otros dos en el centro de la urbe, atendidos por médicos y administrados por las órdenes jesuíticas. Así, los lazaretos que eran dispuestos por los poderes públicos eran emplazados en las afueras de la ciudad, justamente donde vivían los sectores más humildes, pero no sucedía lo mismo con la Iglesia, que como actor importante en las escenas epidémicas, no respondía, en la mayoría de los casos, a las lógicas estatales. Estos emplazamientos tienen una doble lectura: por un lado, que el Consejo de Higiene y los médicos insertos en la municipalidad suponían que el cólera atacaría con mayor contundencia a los sectores sociales menos pudientes, y por lo tanto los lazaretos tendrían la función de aislar a los coléricos que habitaran estas zonas; por otro lado, en relación con la hipótesis planteada, que el cólera debía ser alejado del centro de la ciudad, lugar habitado por los sectores dominantes y llevado a su periferia, habitada por los sectores dominados. La segunda de estas lecturas parece la más verosímil, ya que los dos lazaretos estatales se encontraban en la misma región,

${ }^{79}$ Povernir. 24 de noviembre de 1886. 
es decir al sudeste de la ciudad, mientras que la población ubicada al norte y al oeste estaba alejada por completo de ellos (Figura 1.).

Figura 1. Plano de la ciudad de Córdoba, Argentina (1890).

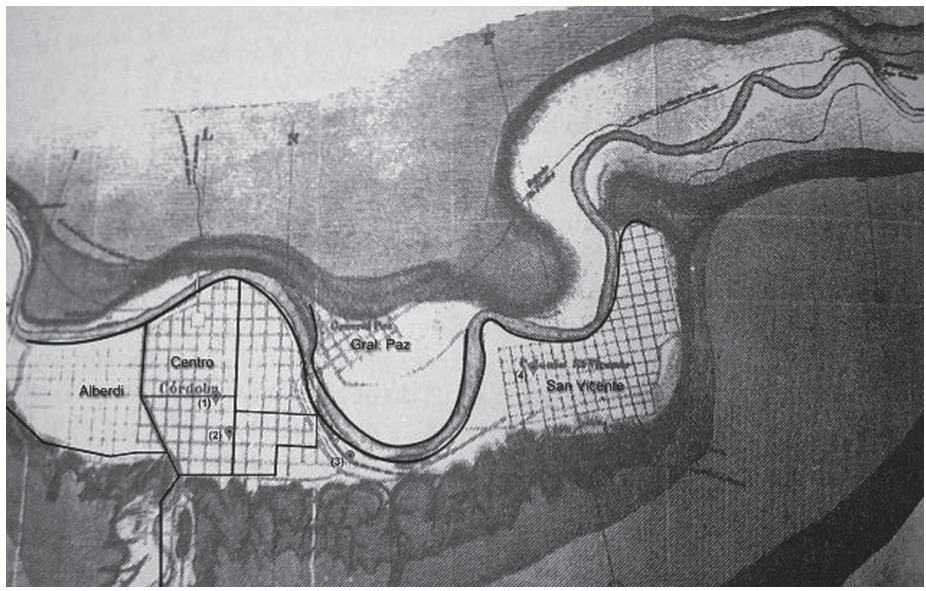

Fuente: elaboración propia sobre mapa archivado en Wikipedia.

1 y 2: lazaretos ubicados en el centro, administrados por la orden jesuita.

3: lazareto administrado por la municipalidad de Córdoba, en la Bajada Pucará.

4: lazareto administrado por el Consejo de Higiene, emplazado en Pueblo San Vicente.

\section{Conclusión}

Las epidemias de cólera en la ciudad de Córdoba fueron elementos catalizadores de los conflictos y las percepciones tanto de médicos como por parte del Estado. La llegada del cólera en 1867 generó una serie de conflictos por la escasa autoridad del Estado para imponer a la medicina académica como un factor presente en la lucha contra la enfermedad. A partir de esta debilidad, los conflictos se suscitaron tanto hacia adentro como hacia fuera del Estado, y la Iglesia, como institución con un importante capital social, logró capitalizar el desenlace de la epidemia, mientras que la medicina académica fracasó en la lucha contra la enfermedad.

Hacia 1886, el Estado había modernizado sus estructuras y la medicina académica lograba imponer sus criterios mediante la conformación y el desarrollo de instituciones como el Consejo de Higiene, cuya autoridad se impuso y todas las instituciones sociales -e incluso el Estado municipal- quedaron bajo sus órdenes. Sin embargo, el Consejo de Higiene impuso una postura de segregación hacia los sectores humildes de la población, quienes a partir de ese momento pasaron a formar parte de las clases peligrosas. De esta forma, todas las instancias de la lucha contra el cólera fueron relativamente obedecidas por las otras instituciones sociales y gubernamentales, pero llevaban implícitas una división social entre los sectores sociales dominantes y los dominados. 
Desde la perspectiva desarrollada a lo largo del artículo, se puede apreciar que si bien los médicos como corporación -inserta a medias en el Estado en la epidemia de 1867- fracasaron como actores monopólicos en el cuidado de la salud, debido a los diferentes conflictos que tuvieron con otros actores estatales y sociales, en la primera epidemia se puede apreciar, en términos de comparación, una visión tal vez más igualitaria en relación a la lucha contra el cólera.

La segunda epidemia, menor en términos de su contundencia, vio surgir una élite médica encaramada burocráticamente en el Estado a través del Consejo Provincial de Higiene, posición que le dio un poder que no se percibe en la anterior epidemia. No obstante, ese poder fue utilizado para generar acciones segregacionistas y discriminatorias hacia ciertos sectores de la sociedad, los desfavorecidos, que habitaban los márgenes de la ciudad y que fueron tratados como clases que era portadoras, per se, del mal.

\section{Bibliografía}

\section{Fuentes primarias}

\section{Archivos}

Archivo de la Provincia de Córdoba Libro: t. 5 (asuntos diversos).

Archivo Histórico de la Municipalidad de Córdoba. Libro 2.A.6 F580.

Biblioteca de la Legislatura de la Provincia de Córdoba. Compilación de Leyes y Decretos de la Provincia de Córdoba, 1812-1870.

\section{Publicaciones periódicas}

Diario de la Residencia de Córdoba de la Compañía de Jesús, t. 1 (1859-1868).

Diario El Eco de Córdoba

Diario El Porvenir

\section{Fuentes secundarias}

\section{Libros}

Angueira, María del Carmen. Transformaciones de la ciudad de Córdoba: factores operativos (1880-1914). Buenos Aires: Centro Editor de América Latina, 1988.

Baldwin, Peter. Contagion and the state in Europe.1830-1930. Cambridge: University Press, 2004. 
Boixadós, María Cristina. Las tramas de una ciudad. Córdoba entre 1870 y 1895. Córdoba: Ferreyra, 2000.

Chaloub, Sydney. Ciudade febril. Cortiços e epidemias na Corte Imperial. São Paulo: Compania das Letras, 1996.

Chevallier, Luis. Classes laborieuses et classes dangereuses à Paris pendant la première moitié du XIXe siècle. Paris: Plon, 2002 (1958).

Garzón Maceda, Félix. La medicina en Córdoba, t.III. Buenos Aires: Editorial Talleres Gráficos Rodríguez Giles, 1917.

González Leandri, Ricardo. Curar, persuadir, gobernar. La construcción histórica de la élite médica en Buenos Aires, 1852-1886. Madrid: CSIC, 1999.

Penna, José. El cólera en la República Argentina. Buenos Aires: Editorial Antonio Peuser, 1897.

\section{Capítulos de libros}

Carbonetti, Adrián. "Políticas estatales y medicina frente a la epidemia de cólera de 1867-68 en Córdoba y Rosario", en Carbonetti, Adrián (comp.), Historias de enfermedad en Córdoba desde la colonia hasta el siglo XX. Córdoba: Editorial de la Municipalidad de Córdoba, 2007.

Carrillo, Ana María. "La epidemia de cólera de 1833 en el Estado de México", en Cuenya, Miguel Ángel; Malvido, Elsa; Lugo, Concepción; Carrillo, Ana María y Oliver Sánchez, Lilia, El cólera de 1833. Una nueva patología en México. Causas y efectos. México: Instituto Nacional de Antropología e Historia, 1992.

Evans, Richard J. "Epidemics and revolutions: cholera in nineteenth-century Europe". en Ranger, Terence y Slack, Paul (eds.), Epidemics and ideas: essays on the historical perception of pestilence. Cambridge: University Press, 1992.

Prieto, Agustina. "Rosario. Epidemias, Higiene e higienistas en la segunda mitad del siglo XX", en Zaida Lobato, Mirta, Política, médicos y enfermedades. Buenos Aires: Biblos, 1997.

Suriano, Juan. "Introducción: una aproximación a la definición de la cuestión social en Argentina", en Suriano, Juan (comp.), La cuestión social en la Argentina 18701943. Buenos Aires: La Colmena, 2000.

\section{Artículos en revistas}

Álvarez, Adriana. "El rol de los lazaretos en el control del cólera y la fiebre amarilla, Buenos Aires 1870-1915”, en História Revista, vol. IX, núm. 2, 2004. 
Medicalización y cólera en Córdoba a fines del siglo XIX. Las epidemias...

Álvarez, Adriana. "La aparición del cólera en Buenos Aires (Argentina), 1865-1996", en Historelo, Revista de Historia Regional y Local, vol. IV, núm. 8, 2012.

Carbonetti, Adrián. "La tuberculosis en Córdoba. La construcción de un espacio marginal”, en Estudios, Revista del Centro de Estudios Avanzados, núm. 9, 1998.

Carbonetti, Adrián. "La conformación del sistema sanitario de la Argentina: el caso de la provincia de Córdoba, 1880-1926", en Dynamis. Acta Hispanica ad Medicinae Scientiarumque Historiam Illustrandam, vol. XXV, 2005.

Carbonetti, Adrián. "Cólera y conflicto en la ciudad de Córdoba, Argentina (18671868)", en Boletín Mexicano de Historia y Filosofía de la Medicina. $2^{a}$ época, vol. X, núm. 2, 2007.

Carbonetti, Adrián y Rodríguez, María Laura. "Las epidemias de cólera en Córdoba a través del periodismo: la oferta de productos preservativos y curativos durante la epidemia de 1867-68", en Revista História, Ciências, Saúde-Manguinhos, vol. XIV, núm. 2, 2007.

Crespo Cossio, Pedro. "Aportes acerca de la incidencia de la epidemia de cólera de 1867 en el Departamento Totoral y población del mismo nombre”, en Ciencia Médica Córdoba, Vol. XXXVIII, 1980.

Folquer, Cynthia. "Colera morbus y cólera divina. Miedo a la muerte e imaginario religioso en Tucumán (Argentina) a fines del siglo XIX”, en Boletín Americanista, año LXI, núm. 62, 2011.

Gargullo, María Cecilia. "El cólera: oportunidades de control y resistencias populares. Tucumán 1886-1887”, en Estudios Sociales, núm. 41, 2011.

Goldman, Noemí. "El levantamiento de Montoneras contra «Gringos» y «Masones» en Tucumán, 1887. Tradición oral y cultura popular”, en Boletín del Instituto de Historia Argentina y Americana Dr. E Ravignani, tercera serie, núm. 2, 1990.

González Leandri, Ricardo. “Académicos, doctores y aspirantes. La profesión médica y la reforma universitaria de Buenos Aires, 1871-1876", en Entrepasados, año VI, núm. 12, 1997.

González Leandri, Ricardo. "La higiene antes de los médicos higienistas. Buenos Aires: 1850-1870. Las epidemias”, en Desmemoria, año V, núm. 18, 1998.

González Leandri, Ricardo. "La consolidación de una inteligentzia médico profesional en Argentina, 1880-1900", en Diálogos, Revista Electrónica de Historia, vol. VII, núm. 1, 2006. 
González Leandri, Ricardo. "El Consejo Nacional de Higiene y la consolidación de una élite profesional al servicio del Estado. Argentina, 1880-1900", en Anuario de Estudios Americanos, t. LXI, núm. 2, 2004.

Rosenberg, Charles E. "Cholera in nineteenth-century Europe: A tool for social and economic analysis", en Comparative Studies in Society and History, vol. VIII, núm. 4, 1966.

\section{Otros}

Carbonetti, Adrián. "Los caminos del cólera en Argentina en la segunda mitad del siglo XX". Ponencia presentada en el III Congreso de la Asociación Latinoamericana de Población, Córdoba, 2008.

Kodama, Kaori. “Os impactos da epidemia de cólera no Rio de Janeiro (1855-56) na população escrava: considerações sobre a mortalidade a través dos registros da Santa Casa de Misericórdia”. Ponencia presentada en el $5^{\circ}$ Encontro escravidão e liberdade no Brasil meridional. Universidade Federal do Rio Grande do Sul, Porto Alegre, 2011. 